Перламутров Ю. Н., Ольховская К. Б. ${ }^{*}$ Ляпон А. 0.

Московский государственный медико-стоматологический университет им. А. И. Евдокимова

Министерства здравоохранения Российской Федерации

127473, Российская Федерация, Москва, ул. Делегатская, д. 20, стр. 1

Современные знания патогенеза акне определяют необходимость раннего применения препаратов с противовоспалительной активностью.

Цель исследования: определение эфффективности монотерапии с использованием крема Адаклин при лечении акне у детей подросткового возраста.

Материалы и методы. Всем подросткам с течением акне легкой и средней степени тяжести проводилось обследование с определением дерматологического индекса акне (ДИА), определение уровня продукции сальных желез, тестирование родителей пациентов. Была проведена монотерапия с использованием крема Адаклин.

Результаты исследования. Под наблюдением находилось 60 больных с акне. Формирование клинической ремиссии было зарегистрировано у 78,33 \% подростков. Была отмечена хорошая переносимость терапии и высокий уровень комплаентности.

Заключение: констатирована высокая эффективность и переносимость терапии при использовании крема Адаклин у подростков с акне.

Ключевые слова: дети подросткового возраста, акне, тяжесть течения, крем Адаклин, эффективность

Конфрликт интересов: авторы заявляют об отсутствии потенциального конфрликта интересов, требующего раскрытия в данной статье.

Для цитирования: Перламутров Ю. Н., Ольховская К. Б., Ляпон А. О. Терапия акне у детей подросткового возраста. Вестник дерматологии и венерологии. 2018;94(6):60-66. https://doi.org/10.25208/0042-4609-2018-94-660-66 


\section{Acne therapy in adolescent children}

Yuri N. Perlamutrov, Kira B. Olkhovskaia*, Alexandra 0. Lyapon

A. I. Yevdokimov Moscow State University of Medicine and Dentistry, Ministry of Health of the Russian Federation Delegatskaya str., 20, bldg 1, Moscow, 127473, Russian Federation

Current knowledge of the pathogenesis of acne determines the need for early use of drugs with antiinflammatory activity.

Aim: to determine the effectiveness of monotherapy using Adaklin cream in the treatment of acne in adolescent children.

Material and methods. All adolescents with acne of light and moderate severity were examined to determine the dermatological index of acne (DIA), determine the level of production of sebaceous glands, testing the parents of patients. Monotherapy was performed using Adaklin cream.

Results. 60 patients with acne were under observation. Formation of clinical remission was registered in $78.33 \%$ of adolescents. A good tolerability of the therapy and a high level of compliance were noted. Conclusion: the high efficacy and tolerability of therapy with the use of Adaklin cream in adolescents with acne was stated.

Keywords: adolescent children, acne, severity, Adaklin cream, effectiveness

Conflict of interest: the authors state that there is no potential conflict of interest requiring disclosure in this article.

For citation: Perlamutrov Y. N., Olkhovskaia K. B., Lyapon A. O. Acne therapy in adolescent children. Vestnik Dermatologii i Venerologii. 2018;94(6):60-66. https://doi.org/10.25208/0042-4609-2018-94-6-60-66 


\section{Актуальность}

Акне - распространенное полиморфное воспалительное заболевание сальных желез, развитие которого характерно для 95 \% подростков мужского и $85 \%$ женского пола [1-3]. Психосоциальные отклонения при данном заболевании наиболее выражены в возрасте от 12 до 17 лет (подростковый возраст), а их выраженность соответствует дезадаптации при таких заболеваниях, как диабет, бронхиальная астма и эпилепсия [4]. Наличие акне у детей подросткового возраста может обуславливать формирование аффективных состояний (тревожно-депрессивный синдром, дисморфофобия, психогенные экскориации), которые регистрируются примерно у 50 \% пациентов данной возрастной категории $[5,6]$. Как правило, к 18-20 годам отмечаются признаки спонтанного регресса заболевания. Однако у части пациентов оно приобретает хронический рецидивирующий характер, в отдельных случаях - с формированием к 30-40 годам поздних акне (acnetarda). С возрастом сальные железы постепенно уменьшаются в размерах и подвергаются частичной или полной атрофрии [7]. Таким образом, крайне актуальным является вопрос рассмотрения современных данных патофизиологии заболевания и, как следствие, преимущественное использование в современной практике патогенетически обоснованных и эффективных терапевтических мероприятий с целью быстрого достижения клинического результата и предотвращения фрормирования стойких косметических дефектов.

Клинические проявления акне у подростков наиболее часто коррелируют со стадиями пубертатного периода. В редких случаях манифестация заболевания отмечается до наступления полового созревания, что может являться негативным прогностическим признаком течения акне. Преимущественной локализацией высыпаний на начальном этапе является кожа центральной части лица и ушных раковин, которые представлены закрытыми и открытыми комедонами. При продолжительном течении акне повышается вероятность фрормирования рубцов и вторичной пигментации [8].

Традиционно клинические проявления акне классифрицируют на «невоспалительные» (закрытые и открытые комедоны) и на «воспалительные» (папулы, пустулы, узлы, кисты, фрлегмоны) элементы акне. Термин «невоспалительные элементы акне» по-прежнему используется в согласительных документах и клинических рекомендациях, однако в свете современных представлений о патогенезе заболевания данная градация элементов сыпи при акне является необоснованной. Последние научно-клинические исследования доказали, что фрормированию микрокомедона предшествует субклиническое перифолликулярное воспаление, что определяет комедон как воспалительное поражение структур кожи. Морфологическое и гистохимическое исследование видимо здоровых участков кожи у больных акне выявило экспрессию $\mathrm{CD}^{+} / \mathrm{CD} 4^{+}$-лимфоцитов, макрофрагов, провоспалительных цитокинов (IL1a, IL6, TNF-a) и изменение микроциркуляции, характерное для воспалительного процесса. В исследовании при помощи цифрового фотографирования кожи больных в течение 12 недель было показано, что папулы и пустулы при акне только в $54 \%$ случаев образуются из комедонов, а в $28 \%-$ на неизмененной коже. Данные исследования сыграли решающую роль в деконструкции догмы, что развитие акне обусловлено первичным формированием гиперкератоза и комедоногенеза, и определили, что все этапы специфических изменений кожи при данном заболевании характеризуются субклиническими или активными воспалительными процессами [9-11].

Экспрессия цитокинов происходит в результате активизации Toll-подобных рецепторов 2-го типа (TLR-2) бактериями $P$. acnes через активизацию ядерного фрактора-кВ и фрактора транскрипции-активирующего протеина 1 (АР-1). Под влиянием АР-1 происходит индукция генов матриксных металлопротеиназ, продукты которых вызывают деградацию и повреждение дермального матрикса, что обуславливает формирование рубцов при разрешении как папул и пустул, так и комедонов. По данным исследований, при акне $P$. acnes выделяются только из $17 \%$ фолликулов, а у здоровых - из $12 \%$. При биопсиях кожи не было выявлено существенных различий между содержанием $P$. acnes на неповрежденной коже и в элементах сыпи акне, а часть комедонов, папул и пустул (от 20 до 54 \%) стерильны. Высказывается предположение, что динамика роста бактерий $P$. acnes и других микроорганизмов является не причиной акне, а следствием изменившейся среды сально-волосяного фолликула вследствие воспаления $[12,13]$.

Наиболее выраженным противовоспалительным действием среди препаратов, рекомендованных для лечения акне, обладают антибиотики и ароматические ретиноиды. Учитывая данные о высокой частоте встречаемости антибиотикорезистентных штаммов $P$. acnes, применение топических антибиотиков в качестве монопрепаратов и использование системных антибактериальных препаратов в качестве монотерапии исключено из современных зарубежных и Российских клинических рекомендаций. Важно подчеркнуть, что топические ретиноиды, в частности адапален, доказали свою эффективность в многолетнем клиническом опыте и относятся по настоящее время к рекомендациям уровня «В» (доказательность эффективности основана на результатах клинических исследований хорошего дизайна, но без рандомизации) [14].

Таким образом, на современном этапе базовыми препаратами лечения акне являются топические ретиноиды, которые являются высокоэффективными средствами для лечения акне с легкой степенью воспаления и назначаются дерматологами каждому второму взрослому пациенту. В то же время в современной детской дерматологической практике их назначение ограничено. По данным В. А. Yentzer и соавт. (2008), педиатры прибегают к использованию данной группы лекарственных препаратов только у 12 \% детей с проявлениями угревой сыпи [15].

Целью настоящего исследования являлось определение эффективности монотерапии с использованием крема Адаклин при лечении акне у детей подросткового возраста.

\section{Материалы и методы}

Под наблюдением находилось 60 детей в возрасте от 12 до 17 лет (средний возраст 14,52 $\pm 2,09$ года) с акне легкой и средней степени тяжести, без выявленных отклонений в гормональном статусе. Среди пациентов, вошедших в исследование, было 35 (58,33 \%) юношей и $25(41,67 \%)$ девушек. В рамках протокола исследования был проанализирован анамнез жизни 
100

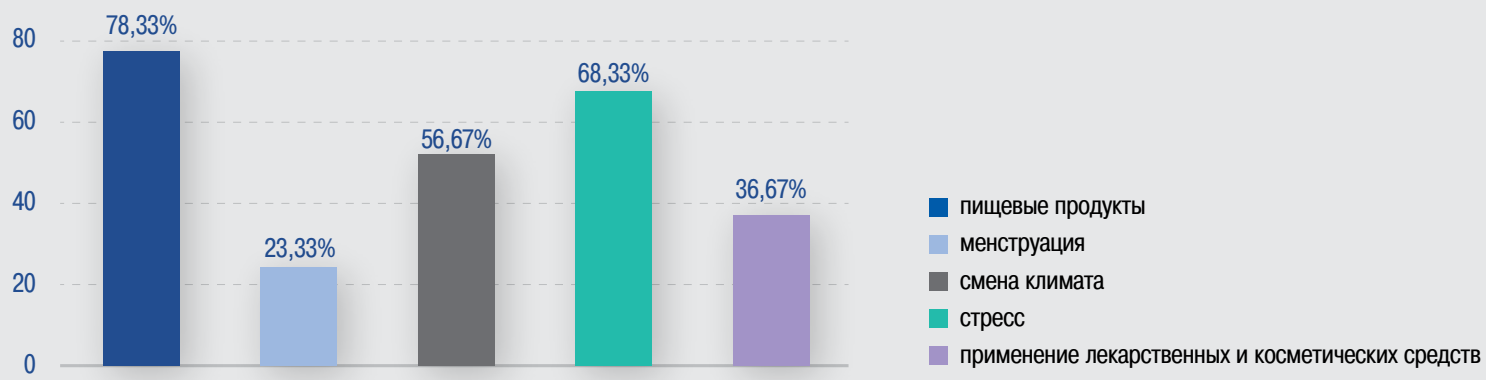

Рис. 1. Триггерные факторы акне у детей подросткового возраста

Fig. 1. Factors triggering acne in teenagers

и заболевания, проводилось тестирование родителей, клинический осмотр больных с определением дерматологического индекса акне (ДИА), учитывающего количество комедонов, папул, пустул и узлов по следующим параметрам: единичные <5 баллов, умеренное количество 6-15 баллов, большое количество $>15$. Интерпретация результатов проводилась по следующим параметрам: ДИА <5 - легкая степень тяжести, ДИА 6-10 - средняя и ДИА 10-15 - тяжелая степень акне [16]. При инструментальном обследовании была определена активность продукции сальных желез при помощи себометра Multi Probe Adapter MPA 5/9 Courage+Khazaka electronic $\mathrm{GmbH}$. Исследование уровня продукции себума осуществлялось фротометрическим методом измерения прозрачности жирных пятен, которые остаются на специальной абсорбирующей ленте после ее контакта с поверхностью образца. Степень прозрачности оценивалась фротометрической оптической системой, встроенной в устройство. После лечения производилась оценка терапевтического эффректа и переносимость проводимой терапии.

\section{Результаты исследования}

На момент скрининга больные предъявляли жалобы на высыпания на коже лица (100\%), в области туловища (35\%), а также на повышенную «сальность» кожи лица и волосистой части головы (55\%). При изучении анамнеза заболевания было установлено, что длительность течения акне составляла от 4 месяцев до трех лет (в среднем составила 2,17 $\pm 0,38$ года). При регистрации данных семейного анамнеза наличие заболевания у родителей было установлено у 49 (81,67\%) больных. Были определены основные триггеры возникновения и рецидивов заболевания. В подавляющем большинстве обострению акне способствовала погрешность в питании, которая заключалась в чрезмерном употреблении пищи, богатой углеводами, и цельного молока. Реже отмечалось воздействие на течение дерматоза смены климата, стресса, применение лекарственных препаратов и косметических продуктов, а также гормональных колебаний (рис. 1).

Перед началом лечения были проанализированы методы предшествующей терапии. Было установлено, что в 68,33 \% случаев (41 больной) для коррекции изменений кожи родителями и пациентами использовались лечебные косметические средства, 5 (8,33 \%) - применяли топические антибиотики, 8 (13,33\%) - препараты на основе азелаиновой кислоты, 6 (10\%) - на основе адапалена. При этом только 14 (23,33 \%) человек были консультированы врачами. Преимущественно пациенты и их родители использовали информацию о заболевании и методах его терапии из интернет-ресурсов и телевизионной рекламы. В этой связи родители были протестированы в отношении их информативности о причинах и методах лечения акне (табл. 1).

Было установлено, что представление об акне у тестируемых было весьма ограниченным и в подавляющем большинстве родители не обладали информацией об истинных причинах заболевания - 47 (78,33\%). При этом информативность о методах лечения была отличной у 14 (23,33 \%) родителей, однако отсутствие знаний о клинических подходах к терапии акне были отмечено у $33(55,00 \%)$ родственников. Вследствие установленной низкой информативности родителей о заболевании был выявлен и объяснен высокий удельный вес приверженности подростков к пище, богатой «быстрыми» углеводами (44 (73,33 \%) и молочными продуктами $(29(48,33 \%))$.

Таблица 1. Инсрормативность родителей подростков о причинах и методах лечения акне

Table 1. Awareness demonstrated by the teenagers' parents about the reasons and methods of acne treatment

\begin{tabular}{|c|c|c|c|}
\hline Информативность о причине акне & Родители $(n=60)$, абс. (отн.) & Информативность о лечении акне & Родители $(n=60)$, абс. (отн.) \\
\hline Отсутствует & $47(78,33 \%)$ & Отсутствует & $33(55,00 \%)$ \\
\hline Удовлетворительная & $9(15,00 \%)$ & Удовлетворительная & $9(15,00 \%)$ \\
\hline Хорошая & $4(6,67 \%)$ & Хорошая & $4(6,67 \%)$ \\
\hline Отличная & - & Отличная & $14(23,33 \%)$ \\
\hline
\end{tabular}




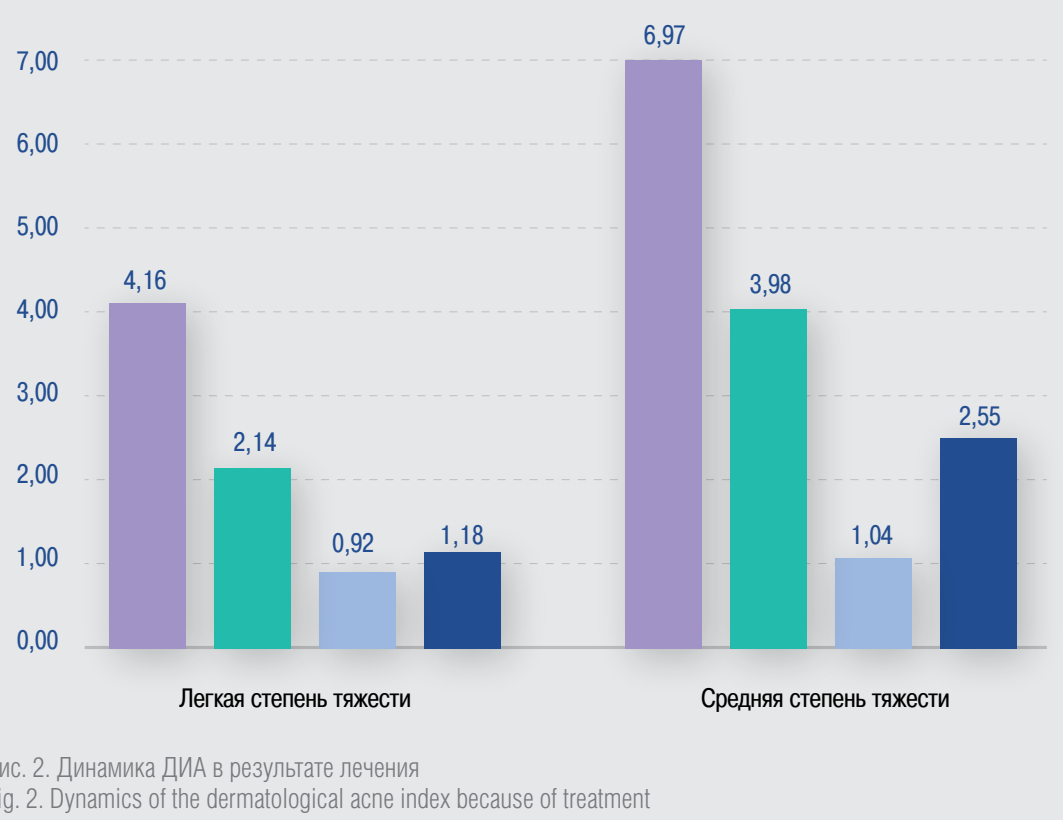

Всем больным в рамках исследования был рекомендован рациональный уход за кожей с использованием специализированных косметических средств, предназначенных для жирной и проблемной кожи, рационализация режима питания детей. В качестве лечебного средства был применен крем Адаклин 1 раз в день, тонким слоем на очищенную кожу в течение 4 месяцев, с последующим назначением поддерживающей терапии с использованием крема Адаклин 3 раза в неделю в течение 6 месяцев.

Крем Адаклин содержит 0,1\% адапалена, который относится к III поколению производных витамина А (полиароматические ретиноиды). Адапален (Адаклин) имеет ряд свойств и преимуществ перед ретиноидами первого и второго поколения, одним из самых значи- мых которых является доказанное более выраженное противовоспалительное действие. Благодаря селективному связыванию с особыми ядерными RAR-g-peцепторами клеток поверхностных слоев эпителия адапален способен наиболее эффрективно регулировать процессы терминальной дифференцировки кератиноцитов, нормализовать процессы отшелушивания роговых чешуек и, следовательно, воздействовать на гиперкератоз в области устья волосяного фолликула. Следствием этого являются удаление участков фолликулярного гиперкератоза (кератолитический эффрект) и предотвращение образования новых микрокомедонов (комедонолитический эфффект), в результате чего он может применяться в качестве монотерапии при легкой и средней степени тяжести течения любых

Таблица 2. Динамика показателей себометрии в результате терапии

Table 2. Dynamics of sebometry indicators as a result of therapy

\begin{tabular}{|c|c|c|}
\hline Лоб & Легкая степень тяжести акне & Средняя степень тяжести акне \\
\hline До лечения & $61,16 \pm 3,07$ & $88,14 \pm 3,09$ \\
\hline Через 8 недель & $42,14 \pm 01,11^{*}$ & $44,61 \pm 3,17^{*}$ \\
\hline Через 16 недель & $55,04 \pm 2,08^{*}$ & $50,12 \pm 2,13^{*}$ \\
\hline Через 6 месяцев после окончания лечения & $55,39 \pm 5,19$ & $58,31 \pm 5,12^{*}$ \\
\hline Правая щека & Легкая степень тяжести & Средняя степень тяжести \\
\hline До лечения & $51,11 \pm 1,44$ & $58,99 \pm 6,99$ \\
\hline Через 8 недель & $33,14 \pm 1,05^{\star}$ & $36,14 \pm 2,07^{*}$ \\
\hline Через 16 недель & $39,31 \pm 2,15^{\star}$ & $41,12 \pm 1,14^{*}$ \\
\hline Через 6 месяцев после окончания лечения & $44,09 \pm 2,17^{*}$ & $45,31 \pm 3,94^{\star}$ \\
\hline Левая щека & Легкая степень тяжести & Средняя степень тяжести \\
\hline Через 8 недель & $31,09 \pm 2,18^{*}$ & $33,17 \pm 1,95^{\star}$ \\
\hline Через 16 недель & $38,61 \pm 2,54^{*}$ & $38,12 \pm 4,83^{*}$ \\
\hline Через 6 месяцев после окончания лечения & $41,32 \pm 2,57^{*}$ & $46,31 \pm 2,07^{*}$ \\
\hline
\end{tabular}


форм акне [17]. Крем оптимален для нормальной и склонной к сухости кожи.

В результате проводимой терапии была зарегистрирована клиническая эффективность проводимой терапии у всех пациентов (рис. 2).

При легкой степени тяжести через два месяца снижение средних значений ДИА составило 48,56 \% и через 4 месяца - 77,88 \%. В группе больных со средней степенью тяжести показатели дерматологического индекса акне снижались менее интенсивно, однако к концу терапии не отличались от результатов в группе с легким течением заболевания, а общая депрессия его значений составила 85,08 \%. При проведении интермиттирующего курса поддерживающей терапии показатели ДИА увеличились, но достоверно отличались от их уровня до лечения в обеих группах.

Клинические результаты лечения коррелировали с показателями себометрии (табл. 2).

Из таблицы следует, что монотерапия с использованием крема Адаклин способствовала достоверному снижению продукции кожного сала уже через 8 недель от начала терапии, при продолжении которой динамика в отношении данных показателей не отмечалась, однако уровень секреции сальных желез сохранял достоверно более низкие значения, чем до начала терапии.
Анализируя переносимость проводимой монотерапии кремом Адаклин у детей подросткового возраста, были зарегистрированы ожидаемые нежелательные явления: ретиноевый дерматит - у 39 (65,00 \%) больных, повышенная фоточувствительность кожи у $8(13,33 \%)$ и реакция “обострения» - у 21 (35,00 \%) пациента. Все нежелательные явления со стороны кожи легко переносились пациентами.

Хорошая переносимость при применении Адапалена в форме крема обуславливает его возможность применения в качестве средства для поддерживающей терапии с целью профилактики рецидивов акне, в том числе после отмены системного изотретиноина в течение длительного времени (от 6 месяцев и более, ежедневно или по интермиттирующей схеме - 2 раза в неделю) [18].

\section{Заключение}

Результаты полученных нами данных указывают на то, что терапия Адаклином у детей подросткового возраста отмечалась длительным эффректом у 47 (78,33\%) больных и не было резистентности к препарату. Удобство нанесения Адаклина (1 раз в сутки), хорошая переносимость и результативность лечения обусловили комплаентность 52 (87\%) больных.

\section{Литература/References}

1. Pawin H., Chivot M., Beylot C. et al. Living with acne. A study of adolescents personal experiences. Dermatology. 2007;215(4):308-314. D0l: $10.1159 / 000107624$

2. James W. D. Clinical practice. Acne. $N$ Engl J Med. 2005;352(14):1463-1472. DOI: 10.1056/NEJMcp033487

3. Thiboutot D. M. Overview of acne and its treatment. Cutis. 2008;81(Suppl. 1):3-7.

4. Mallon E., Newton J. N., Klassen A., Stewart-Brown S. L., Ryan T. J., Finlay A.Y. The quality of life in acne: a comparison with general medical conditions using generic questionnaires. $\mathrm{Br} \mathrm{J}$ Dermatol. 1999;140(4):672-676. DOI: 10.1046/j.1365-2133.1999.02768.x

5. Baldwin $H$. E. The interaction between acne vulgaris and the psyche. Cutis. 2002;70(2):133-139.

6. Gupta M. A., Gupta A. K. Depression and suicidal ideation in dermatology patients with acne, alopecia areata, atopic dermatitis and psoriasis. Br J Dermatol. 1998;139(5):846-850. DOI: 10.1046/j.13652133.1998.02511.x

7. Адаскевич В. П. Акне вульгарные и розовые. М.: Медицинская книга, 2005. [Adaskevich V. P. Acne vulgaris and rosacea. Moscow: Medicinskaya kniga, 2005. (In Russ.)]

8. Krowchuk D. P. Managing adolescent acne: a guide for pediatricians. Pediat Rev. 2005;26(7):250-261. DOI: 10.1542/pir.26-7-250

9. Jeremy A. H., Holland D. B., Roberts S. G., Thomson K. F., Cunliffe W. J. Inflammatory events are involved in acne lesion initiation. J Invest Dermatol. 2003;121(1):20-27. D0I: 10.1046/j.1523-1747.2003.12321.x

10. Do T. T., Zarkhin S., Orringer J. S. et al. Computer-assisted alignment and tracking of acne lesions indicate that most inflammatory lesions arise from comedones and de novo. J Am Acad Dermatol. 2008:58(4):603-608. DOI: 10.1016/s0093-3619 (09)79319-0
11. Weiss J. S. Messages from molecules: deciphering the code. J Drugs Dermatol. 2013;12(6):70-72.

12. Zouboulis C. C. Propionibacterium acnes and sebaceous lipogenesis: a love-hate relationship? J Invest Dermatol. 2009;129(9):20932096. DOI: 10.1038/jid.2009.190

13. Shaheen B., Gonzalez M. A microbial aetiology of acne: what is the evidence? Br J Dermatol. 2011;65(3):474-485. D0I: 10.1111/j.13652133.2011.10375.x

14. Перламутров Ю. Н., Ольховская К. Б. Терапия больных с тяжелой и средней степенью тяжести акне. Вестник дерматологии и венерологии. 2015;(3):141-146. [Perlamutrov Yu. N., Olhovskaya K. B. Treatment of patients with severe and moderate acne. Vestn Dermatol Venerol. 2015;(3):141-146. (In Russ.)]

15. Yentzer B. A., Irby C. E., Fleischer A. B., Feldman S. R. Differences in acne treatment prescribing patterns of pediatricians and dermatologists: an analysis of nationally representative data. Pediatric dermatology. 2008;25(6):635-639. D0I: 10.1111/j.1525-1470.2008.00790.x

16. Игнатьев Д. В., Кочергин Н. Г. Дерматологические индексы в доказательной медицине. IX Всероссийский съезд дерматовенерологов. 2005;2:11-12. [Ignatev D. V., Kochergin N. G. Dermatological indices in evidence based medicine. IX Vserossiyskiy s'ezd dermatovenerologov. 2005;2:11-12. (In Russ.)]

17. Аравийская Е. Р. Современный взгляд на лечение акне: состояние проблемы и новые возможности. Лечащий врач. 2003;(04/03):4-6. [Aravijskaya E. R. Modern view on acne treatment: the state of the problem and new opportunities. Lechashchij vrach. 2003;(04/03):4-6. (In Russ.).]

18. Nast A., Dreno B., Bettoli V. et al. European evidence-based (S3) guidelines for the treatment of acne. J Eur Acad Dermatol Venereol. 2012;26(Suppl. 1):20. DOI: 10.3410/f.14260957.15768252 


\section{Информация об авторах}

Юрий Николаевич Перламутров - д.м.н., профессор, заведующий кафедрой кожных и венерических болезней Московского государственного медико-стоматологического университета им. А. И. Евдокимова Министерства здравоохранения Российской Федерации

Кира Брониславовна Ольховская* - к.м.Н., доцент кафедры кожных и венерических болезней Московского государственного медикостоматологического университета им. А. И. Евдокимова Министерства здравоохранения Российской Федерации; e-mail: olhovskaya_kira@mail.ru

Александра Осиповна Ляпон - к.м.н., ассистент кафедры кожных и венерических болезней Московского государственного медикостоматологического университета им. А. И. Евдокимова Министерства здравоохранения Российской Федерации

\section{Information about the authors}

Yuri N. Perlamutrov - Dr. Sci. (Med.), Prof., Head of the Department of Skin, A. I. Yevdokimov Moscow State University of Medicine and Dentistry, Ministry of Healthcare of the Russian Federation

Kira B. Olkhovskaia* - Cand. Sci. (Med.), Associate Professor of the Department of Skin and Venereal Diseases, A. I. Yevdokimov Moscow State University of Medicine and Dentistry, Ministry of Healthcare of the Russian Federation; e-mail: olhovskaya_kira@mail.ru

Alexandra 0. Lyapon - Cand. Sci. (Med)., Assistant of the Department of Skin and Venereal Diseases, A. I. Yevdokimov Moscow State University of Medicine and Dentistry, Ministry of Healthcare of the Russian Federation 